\title{
En busca del Apple Tree: una revisión de los primeros años de la masonería inglesa
}

\author{
Searching for the Apple Tree: Revisiting the Earliest Years of \\ Organized English Freemasonry
}

\author{
Andrew Prescott \\ Universidad de Glasgow, Escocia \\ andrew.prescott@glasgow.ac.uk \\ Susan Mitchell Sommers \\ Saint Vincent College en Pennsylvania, Estados Unidos \\ susan.sommers@stvincent.edu
}

Recepción: 20 de agosto de 2017/Aceptación: 5 de octubre de 2017

doi: https://doi.org/10.15517/rehmlac.v9i2.31500

Palabras clave

Masonería; 300 años; Gran Logia; Londres; Taberna Goose and Gridiron.

Keywords

Freemasonry; 300 years; Grand Lodge; London; Goose and Gridiron Tavern.

Resumen

La tradición relata que el 24 de junio de 1717 cuatro logias en la taberna londinense Goose and Gridiron organizaron la primera gran logia de la historia. Esto se sustenta solo en la segunda edición de las Constituciones de Anderson (1738), publicada más de veinte años después de los acontecimientos allí descritos. Anderson no hizo referencia a esa historia en la primera edición de las Constituciones (1723), tampoco otras publicaciones y artículos de prensa de la época. Pero al volver a revisar las fuentes se argumenta que la Gran Logia se creó durante un banquete que tuvo lugar en la Stationer's Hall de Londres el 24 de junio de 1721 cuando el duque de Montague fue elegido gran maestro.

Abstract

The tradition has it that on 24 June 1717 four masonic lodges in London in a meeting at the Goose and Gridiron near St Paul's Cathedral in London established the first Grand Lodge and elected Anthony Sayer as its first Grand Master is entirely dependent on a narrative by James Anderson in the second edition of the Book of Constitutions in 1773.Anderson's narrative contains many internal contradictions and inconsistencies. By revisiting such sources as William Stukeley's account of his initiation in 1721 and an account of the election of the Duke of Montague as Grand Master in the records of the Lodge of Antiquity, it is argued that Grand Lodge was not created in 1717, but rather at the dinner at Stationers' Hall in London on 24 June 1721 when the Duke of Montagu was elected Grand Master.

\section{Introducción}

Una de las ventajas de celebrar aniversarios es que nos permiten reconsiderar y revisar los eventos conmemorados. Así, el aniversario 800 de la Carta Magna en 2015 dio pie a nuevos descubrimientos acerca del origen de lo añadido al documento original de 1215 y de los amanuenses que intervinieron en su redacción; mientras que en 2016 el 
400 aniversario luctuoso de Shakespeare trajo consigo la identificación de una nueva primera edición y, gracias al análisis multi-espectral, se logró fechar el borrador del testamento del bardo de Avon. Esperamos que las celebraciones del tricentenario de la Gran Logia darán, de igual forma, un nuevo ímpetu a las investigaciones de lo que Alfred Robbins 1lamó, en su clásico artículo de 1909, "los primeros años de la masonería inglesa organizada""1.

La innovadora investigación de Robbins acerca de las primeras referencias a la Gran Logia en periódicos de la época, nos muestra cuánto se puede alcanzar mediante el análisis sistemático de las fuentes primarias. Por desgracia, son pocos los investigadores que han seguido las huellas de Robbins. El consenso general se basa aún sobre lo que expresó Albert Calvert en su libro editado en el bicentenario de la Gran Logia, donde puso en tela de juicio que alguna vez se encuentre una evidencia más contundente y auténtica sobre los primeros años de esta organización masónica, que la aportada por James Anderson en la edición de 1738 de las Constituciones ${ }^{2}$. Desde nuestro punto de vista, se puede lograr un análisis más crítico de las fuentes que aún existen sobre la historia de la masonería en Inglaterra en 1723. Además, proponemos que, tras el estudio de dichas fuentes, se obtiene un panorama completamente distinto de la fundación de la Gran Logia del que escribió Anderson. Esperamos que las celebraciones del tricentenario, y el presente trabajo en especial, sirvan para reactivar la investigación de las fuentes primarias sobre los primeros años de la Gran Logia.

Pero comencemos por revisar el texto fundamental. La historia de la formación de la Gran Logia en Londres, fue relatada por primera vez en la edición de 1738 de las Constituciones de Anderson, es decir, más de 20 años después de que sucedieron los hechos que pretende registrar. Anderson relata la ascensión de Jorge I al tronó inglés en 1714, así como la rebelión encabezada por Jacobo Estuardo, el célebre Old Pretender. El autor de las Constituciones nos dice que, en 1716, una vez sofocada la rebelión, las pocas logias que existían en Londres se sintieron abandonadas por el gran maestro Christopher Wren y decidieron "reunirse y cimentarse bajo un gran maestro, que fuera el centro de unión y armonía"3. A continuación, Anderson enlista las cuatro logias que se reunieron ${ }^{4}$. En primer lugar, la logia de la cervecería Goose and Gridiron ${ }^{5}$, del área

\footnotetext{
${ }^{1}$ Alfred Robbins, "The Earliest Years of English Organized Freemasonry", Ars Quatuor Cororonati -a partir de ahora $A Q C-22$ (1909): 67-89.

${ }^{2}$ Albert F. Calvert, The Grand Lodge of England 1717-1917 (Londres: Herbert Jenkins, 1917), 1.

${ }^{3}$ James Anderson, The New Book of Constitutions of the Antient and Honourable Fraternity of Free and Accepted Masons (Londres: Caesar Ward and Richard Chandler, 1738), 109-110. A pesar de que existen ediciones en español de esta obra, se ha optado por hacer traducciones propias de los fragmentos citados por los autores del presente trabajo, con el fin de respetar la fuente original consultada por ellos (N. del T.).

${ }^{4}$ Robert Freke Gould, The Four Old Lodges, Founders of Modern Freemasonry, and their Descendants (Londres: Spencer's Masonic Depot, 1879). Un resumen conciso de lo descubierto por Gould se encuentra en "Fortitude and Old Cumberland Lodge No. 12", Collected Essays and Papers relating to Freemasonry (Belfast y Londres: William Tait, Spencer \& Co., 1913), 183-187.

${ }^{5}$ Se respetarán los nombres en inglés de las logias, tabernas, cervecerías, calles y lugares de referencia para facilitar su ubicación en otras fuentes y medios (N. del T.).
} 
conocida como St. Paul's Churchyard. La sucesora de esta logia es la Antiquity no. 2. En segundo lugar, la logia de la cervecería Crown, ubicada en Parker's Lane, cerca de Drury Lane. Esta logia se extinguió por falta de miembros poco después de 1736. En tercer lugar, la logia de la taberna Apple Tree, situada en Charles Street, en el área de Covent Garden. La historia de esta logia es complicada, pero puede decirse que es la antecesora de la logia Fortitude and Old Cumberland no. 12. Y, por último, la logia de la taberna Rummer and Grapes de la calle Channel Row, en la zona de Westminster. La descendiente de esta logia es la Royal Somerset House and Inverness no. 4.

Anderson relata que estas cuatro logias se reunieron en la taberna Apple Tree de Charles Street. En dicha reunión también se dieron cita "algunos viejos hermanos" que, aparentemente, no eran miembros de ninguna de las cuatro logias. La reunión fue presidida por el más viejo de los maestros masones. Anderson afirma que la asamblea "se constituyó como una gran logia provisional en debida forma". Como bien lo explicó Begemann hace ya algún tiempo ${ }^{6}$, esta afirmación es pura jerigonza legal utilizada por Anderson para demostrar la continuidad con los grandes maestros anteriores. Sin embargo, el resultado de dicha reunión descrita por Anderson fue muy claro. Las logias revivieron las comunicaciones trimestrales de la Gran Logia, accedieron a realizar una reunión y banquete anuales y decidieron elegir a un gran maestro. Según Anderson, el 24 de junio de 1717 se llevó a cabo un banquete de libres y aceptados masones en la cervecería Goose and Gridiron y que, antes de la cena, el maestro que había presidido la reunión en la taberna Apple Tree propuso candidatos para el puesto de gran maestro. Se llevó a cabo una votación y resultó electo Anthony Sayer.

El relato de Anderson tiene connotaciones topográficas muy importantes. Dos de las logias estaban ubicadas en Covent Garden, un área que con sus populosas plazas y mercados era el epítome de lo que el historiador Vic Gatrell describió como la "infinita energía y acompasado desorden" de la vida urbana del siglo XVIII ${ }^{7}$. Este historiador sudafricano nos muestra cómo la zona de Covent Garden, con su interesante mezcla social de mercaderes, libreros, artistas, actores, prostitutas y carteristas, se puede considerar como el primer barrio artístico y bohemio. Una de las cuatro logias que enlista Anderson se reunía en la taberna Crown en Parker's Lane, una callejuela estrecha "de poca monta" ${ }^{\text {y }}$ cercana a los famosos "Hundreds of Drury", una de las partes más decadentes de Covent Garden ${ }^{9}$. Probablemente se trate de la misma taberna Crown mencionada en un caso de 1722 presentado en Old Bailey, la corte criminal de

\footnotetext{
${ }^{6}$ Wilhelm Begemann, Early History and Beginnings of Freemasonry in England, trad. Lionel Vibert, manuscrito resguardado en la Library and Museum of Freemasonry de Londres, 575. Este manuscrito es una traducción de los dos volúmenes de Begemann, Vorgeschichte und Anfänge der Freimaurerei in England (Berlín: E. S. Mittler, 1909) que estaba siendo preparada para su publicación por la logia Quatuor Coronati, pero que nunca vio la luz debido a la negativa de publicar el trabajo de un investigador alemán durante la primera guerra mundial.

${ }^{7}$ Vic Gatrell, The First Bohemians: Life and Art in London's Golden Age (Londres: Allen Lane, 2013), 4.

${ }^{8}$ John Stow y John Strype, A Survey of the Cities of London and Westminster (Londres: A. Churchill, J. Knapton, 1720), vol. II, 76.

${ }^{9}$ Gatrell, First Bohemians, 29-44.
} 
Londres entre 1674 y 1913, en el que una sirviente del tabernero fue acusada de robarle una caperuza a su patrón. En su defensa, la sirviente argumentó que cualquiera pudo haber robado la prenda, dado que la taberna Crown era un lugar sin orden, y declaró que "lo peor de lo que podía ser culpable era de asistir a su amo para conseguir prostitutas para los caballeros" $"$.

Charles Street, donde se supone que se llevaron a cabo las conversaciones para formar una gran logia hace 300 años, estaba en el corazón de Covent Garden ${ }^{11}$. En 1844 esta calle cambió de nombre y en la actualidad forma parte de la calle Wellington, que es la continuación de la calle Bow y que la conecta con The Strand y el puente Waterloo. Para aquellos que estén familiarizados con Covent Garden, es la parte de la calle Wellington al norte de la calle Tavistock, donde está la entrada al antiguo Flower Market y el London Film Museum. Charles Street era un reflejo de la importancia de Covent Garden como barrio de artistas. Los pintores Thomas Gibson e Isaac Collivoe padre vivieron ahí, y los cuadros de Collivoe se vendieron después de su muerte, en 1726, en una casa de subastas y sala de conciertos, sobre la misma calle Charles, que se llamaba "The Vendu" ${ }^{2}$. El grabador Claude du Bosc tenía una tienda en esta calle, en la que alguna vez vendió una traducción de Ceremonies and Religious Customs of the Various Nations of the Known World, obra clave escrita por Bernard Picart y Jean Frédéric Bernard, que contenía una ilustración de una logia masónica ${ }^{13}$. El dramaturgo y poeta laureado Collley Cibber y el actor Barton Booth también vivieron allí. Pero Charles Street también era un reflejo de la extraordinaria mezcla social de Covent Garden. En ella se alojaban la entrada secreta a Hummums, unos baños turcos famosos por ser un centro de prostitución, y el prostíbulo que regenteaba "Mother" Hayward, al cual, tras la muerte de esta en 1743, se le adjudicó un valor de 10000 libras ${ }^{14}$. En una esquina de Charles Street la viuda Hillmann ofrecía su remedio "Prevención Venérea", el cual garantizaba que "infaliblemente conquista y destruye todas las partículas del veneno venéreo" ${ }^{\prime 15}$.

La bulliciosa, energética, en ocasiones terrorífica y muchas veces inmoral vida urbana que se desarrolló en Inglaterra durante el siglo XVIII podía disfrutarse plenamente en Charles Street, el telón de fondo para la reunión que Robert F. Gould

10 Old Bailey Proceedings Online, 7 de septiembre de 1722 versión 7.2, ref. f17220907-1.

${ }^{11}$ Sobre Charles Street, véase "'Bow Street and Russell Street Area: The former Charles Street", en Survey of London: Volume 36, Covent Garden, ed. F. H. W. Sheppard (Londres: London County Council, 1970), 195-196.

${ }^{12}$ Daily Journal, 19 de enero de 1727.

13 Timothy Clayton, "Du Bosc, Claude (b. 1682, d. in or after 1746)", en Oxford Dictionary of National Biography (Oxford: Oxford University Press, 2004), no. índ. 101008118; Lynn Hunt, Margaret Jacob y Winjand Mijnhardt, The Book that Changed Europe: Picart and Bernard's Religious Ceremonies of the World (Cambridge, MA: Harvard University Press, 2010).

${ }^{14}$ Fergus Linnane, Madams: Bawds and Brothel Keepers of London (Stroud: Sutton Publishing, 2005), 37, 95.

${ }^{15}$ London Journal, 7 de octubre de 1721. 
describiría como "el momento más importante de la historia de la masonería"16. Pero, ¿acaso se llevó a cabo dicha reunión en Charles Street? ¿Existía acaso la taberna Apple Tree? Las respuestas a estas preguntas son menos certeras de lo que, a partir de la repetición del argumento de Anderson a lo largo de 300 años, se podría suponer. El relato de la fundación de la Gran Logia en 1716-1717 no se reportó públicamente en ningún lugar antes de la edición de 1738 de las Constituciones. En la edición de 1723 de dicha obra, no se mencionan para nada los sucesos de 1717. Al referirse al reinado de Jorge I, las Constituciones de 1723 apenas y hacen mención de la colocación de la primera piedra de St. Martin-in-the-Fields, en septiembre de 1722, y se asegura que los libres y aceptados masones florecían bajo la dirección de su gran maestro, el duque de Montagu $^{17}$. La única referencia que se hace de algún gran maestro anterior a Montagu es una breve mención de George Payne, quien ocupó el puesto durante las regulaciones de $1720^{18}$. De Anthony Sayer se dice que era vigilante de la logia no. 3, según la lista de logias de la versión de 1723 de las Constituciones, pero en ningún momento se menciona que haya sido gran maestro ${ }^{19}$.

No solo la historia de la fundación de la Gran Logia está ausente en las Constituciones de 1723. Tampoco se hace mención de los numerosos libros y artículos publicados sobre el tema de la masonería entre 1723 y 1738, como el Pocket Companion for Free-Masons de William Smith o Masonry Dissected de Samuel Pritchard. La referencia más temprana a la Gran Logia se hizo en el Post Boy del 24-27 de junio de 1721, donde se publicó una nota sobre el banquete en el que el duque de Montagu fue nombrado gran maestro ${ }^{20}$. El documento más antiguo que se conserva, emitido por la Gran Logia, es una invitación al gran banquete de 1722, que contiene un grabado de John Sturt, el mismo grabador que ilustró la Cyclopedia de Ephraim Chambers $^{21}$. El primer libro de minutas de la Gran Logia comienza el 24 de junio de 1723. La historia de la Apple Tree, la Goose and Gridiron y las demás logias se basa enteramente en el relato de Anderson en sus Constituciones de 1738. La hipótesis ha sido, como bien lo explicó recientemente John Hamill, que "cuando Anderson escribió sus relatos todavía estaban vivos muchos de los que asistieron o que conocieron a quienes estuvieron presentes en la taberna Goose and Gridiron en junio de 1717', y que

\footnotetext{
${ }^{16}$ Gould, Four Old Lodges, 45.

${ }^{17}$ The Constitutions of Free Masons (Londres: William Hunter for John Senex and John Hooke, 1723), 44-48.

${ }^{18}$ The Constitutions of Free Masons, 58.

${ }^{19}$ The Constitutions of Free Masons, 74.

${ }^{20}$ Robbins, "Earliest Years", 68. El reporte publicado en el Post Boy se reimprimió en el Weekly Journal or British Gazetteer, el 1 de julio de 1721, en el Weekly Journal or Saturday's Post, también del 1 de julio de 1721, y en el Ipswich Journal, del 24 de junio de 1721.

${ }^{21}$ Oxford, Bodleian Library, MS. Rawlinson C. 136, f. 5. Dado que este grabado ha sobrevivido hasta nuestros días, parece extraño que Anderson mencione, en la edición de 1738, que se comisionó un nuevo grabado para los boletos del banquete anual de 1723. Book of Constitutions, 115.
} 
lo hubieran rectificado en caso necesario ${ }^{22}$. Sin embargo, esta suposición es un tanto aventurada.

En febrero de 1735, Anderson interpuso dos quejas ante la Gran Logia: una debido a que la primera edición de las Constituciones estaba agotada, y otra porque William Smith había plagiado material de su libro para redactar Free Mason's Pocket Companion $^{23}$. Según Anderson, las Constituciones eran "su propiedad exclusiva". Pero en realidad no lo eran. El formato y el texto que se lee en la página de título de la obra dejan en claro que los editores y titulares de los derechos de autor eran John Senex y John Hooke ${ }^{24}$. Anderson, quien en ese entonces trabajaba con Hooke en la traducción de Conversations in the Realms of the House of the Dead de David Fassmann, recibio su pago, de parte de Hooke y Senex, bajo la forma de "pago por página" ("copy money") y no por el volumen completo de las Constituciones ${ }^{25}$. Así, por mucho que Anderson hubiera reclamado a la Gran Logia, la edición de 1723 no era de su propiedad.

Dos figuras clave en la edición de 1738 de las Constituciones fueron los editores Richard Chandler y Caesar Ward. Chandler había sido aprendiz de Hooke, y tras la muerte de este, en 1730, adquirió su empresa y muchos de los derechos de autor que detentaba $^{26}$. En 1734, Chandler se asoció con su cuñado, Caesar Ward, y buscaron expandir su negocio a York $^{27}$. Las negociaciones de ambos editores para comprar el

${ }^{22}$ John Hamill, "When History is Written”, Freemasonry Today, 7 de junio de 2016.

${ }^{23}$ Quatuor Coronatorum Antigrapha -a partir de ahora QCA- 10 (1913): 244-245.

${ }^{24} \mathrm{Si}$ la logia o Anderson hubieran sido los titulares de los derechos de autor de las Constituciones de 1723, entonces la página de título habría dicho algo como "Impreso para el autor (o la Gran Logia) y vendido por John Senex y John Hooke", como se ve, por ejemplo, en la obra de 1725 de William Garbott NewRiver, la cual dice "impreso para el autor y vendido por J. Hooke en The Flower-de-Luce de St Dunstan". Véase M. A. Shaaber, "The Meaning of the Imprint in Early Printed Books", The Library 25 (1944), 120141. James Raven indica que, a principios del siglo XVIII, "los derechos de reproducción de una obra generalmente eran comprados por el librero-editor o por un consorcio de libreros. La mayoría de los autores renunciaba a cualquier reclamo sobre la titularidad; los derechos se dividían en participaciones entre distintos grupos de libreros". Véase James Raven, "The Book Trades", en Books and their Readers in Eighteenth Century England: New Essays, ed. Isabel Rivers (Leicester: Leicester University Press, 2011), 15. Acerca de los "pagos por página", véase Richard Sher, The Enlightenment and the Book: Scottish Authors and their Publishers in Eighteenth-Century Britain, Ireland and America (Chicago y Londres: University of Chicago Press, 2006), 215-216. Tobias Smollett recibió tres guineas por cada página de Complete History of England.

${ }^{25}$ La traducción de la obra de Fassmann tiene una referencia a la elección de un gran maestro por parte de los masones. Véase Prescott, "The Publishers of the 1723 Book of Constitutions", AQC 121 (2008): 160, donde se indica que dicha traducción se publicó en 1719. La fecha correcta de la publicación es 1723 , lo cual se deriva de los anuncios aparecidos en la prensa (en algunos casos, el libro de Fassmann se publicitaba junto con las Constituciones). Véase British Journal, 16 de febrero de 1723; London Journal, 9 de marzo de 1723. El crédito de Anderson como traductor y autor de la referencia a la masonería se hizo público en la reimpresión de 1739 del libro de Fassmann, posterior a la muerte de Anderson, en la página de título. News from Elysium or Dialogues of the Dead (Londres: J. Cecil and F. Noble, 1739). Sobre Fassmann, véase C. Sammons, "David Fassmann's Gespräche in dem Reiche der Toten", Yale University Library Gazette 46 (1972): 176-178; y J. Rutledge, The Dialogue of the Dead in EighteenthCentury Germany (Fráncfort y Berna: Herbert Lang, 1974).

${ }^{26}$ Prescott, "Publishers of 1723 Book of Constitutions", 161-162.

${ }^{27}$ Sobre Ward, véase further C. Y. Ferdinand, "Ward, Caesar (bap. 1710, d. 1759)", en Oxford Dictionary, no. índ. 101064292; y W. G. Day, "Caesar Ward's Business Correspondence”, Proceedings of the Leeds 
York Courant, en enero de 1739, probablemente fueron el motivo por el cual se retrasó la publicación de la nueva edición de las Constituciones, ya que Anderson reportó la obra como lista para imprimirse en enero de 1738, pero se anunció para su venta apenas en enero de 1739. Debido a su amistad con Francis Drake, Ward esperaba que las Constituciones se vendieran bien entre los masones de Yorkshire. La importancia de Chandler y Ward en la producción de las Constituciones de 1738 se hace patente en la suerte que corrió la obra posteriormente. Tras el suicidio de Chandler en 1744 y la bancarrota de Ward en 1746, los ejemplares restantes de las Constituciones de 1738 fueron vendidos a un editor de apellido Robinson, quien al parecer no era masón. Robinson reeditó el libro con su propia página de título y sin hacer referencia a la Gran $\operatorname{Logia}^{28}$.

Al igual que en 1723, fue muy probable que Chandler y Ward le hayan pagado a Anderson por página por su trabajo en las Constituciones de 1738. Los problemas financieros de Anderson, y el hecho de que era un deudor sujeto a las "reglas de The Fleet" 29 , eran un fuerte incentivo para su producción literaria. Tanto él como sus editores, esperaban maximizar las ventas produciendo un volumen más completo y más fidedigno que sus competidores. Los anuncios publicitarios de la obra destacaban que "este nuevo libro es casi del doble de páginas que el anterior, con muchas nuevas informaciones, en especial sobre las transacciones de la Gran Logia desde entonces"30.

El trabajo de Anderson estuvo bajo el escrutinio y la corrección de un grupo de grandes oficiales de la logia, pero no sabemos ni quiénes eran ni si habían tenido algo qué ver en los eventos de 1716-1717. George Payne y Jean-Théophile Desaguliers, dos figuras de capital importancia en los primeros años de la logia, seguían en activo como grandes oficiales hacia 1738-1739. Pero muchos de los otros grandes oficiales se habían iniciado en la masonería tiempo después de la época de la fundación. El hecho de que la Gran Logia estaba algo confusa respecto a lo publicado en la edición de 1723 de las Constituciones, nos habla de que la memoria colectiva de sus primeros años no era muy buena.

Philosophical and Literary Society, Literary and Historical Section 19 (1982): 1-8. El catálogo A catalogue of books printed for Caesar Ward and Richard Chandler, at the Ship between the TempleGates in Fleet-Street, and sold at their Shop at Scarborough, 1734, se encuentra en la British Library: RB 23.a.5967.

${ }^{28}$ QCA 12 (1960), 80-81. John Entick, en su prefacio a The Pocket Companion and History of FreeMasons (Londres: J. Scott, 1754), nos dice que la supervisión de Anderson de la producción de las Constituciones de 1738, fue muy descuidada: "por el motivo que haya sido, ya sea por fuerza de su salud o por confiar en el manejo de extraños, esta obra se publicó en muy malas condiciones. Las regulaciones, que habían sido revisadas y corregidas por el gran maestro Payne, estaban interpoladas en ocasiones y, en otras, el sentido quedo totalmente obscuro y vago".

29 The Fleet era una prisión londinense que albergaba, mayormente, a deudores. Muchos de los prisioneros en realidad no residían dentro de los muros del edificio, sino que vivían en los alrededores, pero tenían que sujetarse a las "reglas de The Fleet" (N. del T.).

${ }^{30}$ Por ejemplo, véase London Daily Post and General Advertiser, 22 de enero de 1739; Country Journal and the Craftsman, 25 de enero de 1739; London Evening Post, 27-30 de enero de 1739. 
Anderson comenzó a involucrarse con la Gran Logia en 1721 y, por ende, no tenía conocimiento directo de los eventos anteriores. Pero, como buen historiador, se dio a la tarea de recolectar testimonios tanto orales como escritos, los cuales intentó empatar. Al final de la edición de 1738 de su libro, Anderson da una lista de sus hermanos que lo habían apoyado durante la preparación de este ${ }^{31}$. En su otra gran obra, Royal Genealogies, aporta una lista similar. La de 1738 no era una lista de miembros, sino más bien una forma de hacer públicas sus conexiones sociales y demostrar su autoridad en la materia. Así, en dicha lista encontramos los nombres del duque de Richmond, el conde de Inchiquin y el conde de Loudon. Otros enlistados, como los grabadores John Pine y Louis-Phillippe Boitard o el impresor Thomas Aris, se mencionan debido a su intervención en la producción del volumen. Algunos otros se añadieron a la lista dado que aportaron información sobre eventos específicos, como William Goston y el científico Erasmus King, amigo de Desaguliers, quienes actuaron como vigilantes durante la iniciación del príncipe de Gales, en $1737^{32}$.

Muchos de los hombres que menciona Anderson, tales como Martin Clare, William Graeme y Edward Hody, se iniciaron en la masonería hacia finales de la década de 1720 y principios de la de $1730^{33}$. Es muy poco probable que Thomas Desaguliers, hijo de Jean-Théophile, que apenas contaba con 17 años de edad y que comenzó a frecuentar las logias en 1738, haya sido de mucha ayuda para las pesquisas de Anderson $^{34}$. De los masones que menciona Anderson, y que se habían iniciado en la masonería a principios de la década de 1720, solamente uno afirmó haber estado presente en los eventos de 1716-1717. Se trata de Jacob Lamball, un carpintero que fue nombrado primer vigilante en la taberna Goose and Gridiron en 1717. Al parecer, Lamball fue la principal fuente de información que tuvo Anderson para los eventos de aquel año. Resulta sorprendente que Anderson no mencionara a Anthony Sayer en su lista de agradecimientos, a pesar de que aún estaba vivo en 1738. Lo anterior se explica por el descrédito en el que cayó Sayer debido a las quejas que se interpusieron en su contra, en 1730, por iniciar masones irregularmente a pesar de haber recibido ayudas de caridad de parte de la Gran Logia. Si Anderson consultó a Sayer, no estaba dispuesto a hacerlo público.

\footnotetext{
${ }^{31}$ Book of Constitutions (1738), 229.

${ }^{32}$ Sobre Erasmus King, véase J. H. Appleby, "Erasmus King: Eighteenth-Century Experimental Philosopher", Annals of Science 47 (1990): 375-392. No queda claro si se trata del mismo William Goston que tuvo problemas legales con John Ward respecto a un proyecto de minería en sus tierras. Ric Berman, The Foundations of Modern Freemasonry: The Grand Architects Political Change and the Scientific Enlightenment (Brighton: Sussex Academic Press, 2012), 167.

${ }^{33}$ A Graeme se le menciona por primera vez en las minutas de la Gran Logia cuando fue nombrado oficial en 1734: $Q C A$ 10, 241; Lo mismo sucede en el caso de Hody: $Q C A$ 10, 254; sobre Martin Clare, véase Prescott, "Clare, Martin", en Charles Porset y Cécile Revauger, Le monde maçonnique des Lumières: Europe-Amériques \& Colonies, Dictionnaire prosopographique (París: Editions Champions, 2013), vol. 1, 808-818.

${ }^{34}$ Audrey T. Carpenter, John Theophilus Desaguliers: A Natural Philosopher, Engineer and Freemason in Newtonian England (Londres y Nueva York: Continuum, 2011), 241.
} 
Hay muchos elementos que desacreditan a Lamball como testigo de los eventos de 1716-1717. A pesar de haber sido nombrado vigilante en 1717, no existe evidencia de su actividad masónica sino hasta marzo de 1735, cuando fungió como primer vigilante en reemplazo de sir Edward Mansell ${ }^{35}$. Esto sucedió en la primera comunicación trimestral inmediatamente después de aquella en la que Anderson propuso una nueva redacción de las Constituciones. Sospechosamente, parecería que el mismo Anderson fue responsable de la reaparición de Lamball en la Gran Logia. No se sabe cómo es que Lamball fue nombrado vigilante en 1735, ya que hay algunos problemas con su historia. En 1717, Lamball era apenas un aprendiz de carpintero, ya que empezó su contrato con John Manwell en marzo de $1714^{36}$. Lamball no se convirtió en independiente registrado en la Carpenters' Company hasta el 6 de junio de $1721^{37}$. Como aprendiz, los tiempos de ocio y descanso de Lamball estaban controlados estrictamente por su maestro ${ }^{38}$, por lo que se antoja difícil que haya podido dedicarse a la organización de la Gran Logia. Pero hay otras anomalías con Lamball. Cuando contrajo matrimonio en $1725^{39}$, declaró ser mayor de 30 años, lo cual significa que tendría unos 19 años cuando se inició como aprendiz, lo cual es mayor que la edad habitual de 14 años. Para 1731, sin embargo, Lamball ya era más próspero y había establecido su propia carpintería en la calle Hyde, de Bloomsbury, y rentaba una casa nueva en Camberwell ${ }^{40}$. Siguió asistiendo a la logia hasta 1745. En 1756, Lamball solicitó ayuda de caridad a la Gran Logia debido a su avanzada edad y a que se encontraba enfermo (al parecer tendría ya 61 años). Recibió diez guineas ${ }^{41}$. Murió tres años después y fue enterrado en la iglesia de St. George, en Bloomsbury ${ }^{42}$.

Anderson también echó mano de fuentes escritas. El gran secretario John Revis le dio acceso a los libros de minutas de la Gran Logia. Al final del primer libro hay una lista de oficiales de la logia, comenzando con Sayer como gran maestro y siguiendo con Lamball y Joseph Elliot como vigilantes ${ }^{43}$. Esta lista fue alterada por Anderson, ya que después del nombre del vigilante William Hawkins, nombrado en 1723, añadió: “quien

\footnotetext{
${ }^{35}$ QCA 10, 247.

36 "Jacob Lamball Son of Nicholas Lamball late of Sellborne in ye.Co [..] of Hants Yeom bound to John Manuel Citizen \& Carpenter", Carpenters' Company, Minute Book of Courts and Committees, marzo 1713/1714, ref. GLCCMC251120116.

${ }^{37}$ Archivo de la Carpenters' Company, ref. GLCCMC251040025.

${ }^{38}$ Joan Lane, Apprenticeship in England 1600-1914 (Londres: UCL Press, 1996), 95-116.

${ }^{39}$ Lamball, declarado como miembro de la parroquia de St. Giles in the Fields, mayor de 30 años y soltero, se casó con Sarah Brown, mayor de 21 años, de la parroquia de St. Paul, Covent Garden, con licencia, el 23 de junio de 1725 en la iglesia de St. Benet's, Paul's Wharf, en Londres. Genealogical Society of Utah, Salt Lake City, FHL microfilms 547508, 574439, 845242.

${ }^{40}$ Daily Advertiser, 5 de marzo de 1731.

${ }^{41}$ QCA 12, 96-97.

42 London Metropolitan Archives, P82/GEO1/056: St George, Bloomsbury, registro de entierros, febrero de 1731 a marzo de 1761 .

${ }^{43}$ Agradecemos a Diane Clements y a Susan Snell por permitirnos consultar el libro original en la Library and Museum of Freemasonry.
} 


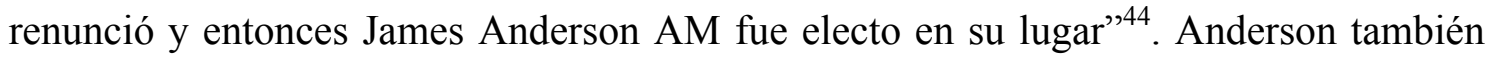
añadió las iniciales "A.M.F.R.S." después del nombre de Martin Clare, registrado en 1734. Sin importar lo que opinemos de las alteraciones hechas por Anderson al libro, esto nos confirma que la lista se recopiló independientemente de su investigación y que la empleó como fuente. Al igual que el resto de las minutas, la lista de oficiales de la Gran Logia fue escrito del puño y letra de William Reid, quien fue nombrado gran secretario en diciembre de $1727^{45}$. El tipo de letra y el color de la tinta sugieren que Reid insertó la lista en el libro de minutas después de 1731, posiblemente tan tarde como 1734. Así tenemos que esta lista, a pesar de ser independiente del trabajo de Anderson, también se recopiló mucho tiempo después de la fundación de la Gran Logia y, probablemente, reflejaba el estado de ánimo al interior de esta en la década de 1730.

Anderson hizo lo más que pudo para hilar los relatos de gente como Lamball y los fragmentos de información escrita, tales como los ya mencionados libros de minutas. Por desgracia, Anderson sucumbió a la tentación de actualizar y pulir sus fuentes. Añadió información sobre Joseph Elliot, uno de los vigilantes de la época de Sayer, afirmando que era capitán. Sin embrago, no existe información al respecto en los archivos militares. Anderson también añadió que John Cordwell, nombrado vigilante de la logia en 1718, era "carpintero de cabildo" ". Cordwell era en realidad miembro del gremio de carpinteros de The City en 1738, cuando se involucró en una batalla legal con el alcalde y el cabildo debido a discrepancias en los precios de la madera en el contrato para la nueva Mansion House ${ }^{47}$, pero obtuvo este puesto en 1722 y no antes ${ }^{48}$. De igual forma, en la lista de oficiales se menciona a Richard Ware como vigilante de la logia en 1720, y Anderson nos informa que era matemático. No hay registros de las aportaciones de Ware a las matemáticas, pero se sabe que era un exitoso librero y que muchas de las obras que publicó versaban sobre perspectiva y arquitectura ${ }^{49}$.

Existen muchas contradicciones en el recuento de los primeros años de la Gran Logia hecho por Anderson. Por ejemplo, afirma que el primer acto de Sayer como gran maestro fue revivir las comunicaciones trimestrales, pero solamente reporta los

\footnotetext{
${ }^{44} Q C A$ 10, xxiii-xxiv, 196. Songhurst sugiere que Anderson también borró la frase "quien substituyó a Mr. Hawkins" en la minuta en la que aparece como primer vigilante, del 24 de junio de 1723. Esto supone que Anderson nunca fue electo vigilante, pero que actuó como tal a partir del 28 de agosto de 1730.

${ }^{45}$ QCA $10, \mathrm{XXV}$.

46 "City Carpenter" se refiere a aquellos miembros del gremio de carpinteros que obtenían puestos públicos en "the City", el centro administrativo y financiero que, incluso en la actualidad, es independiente de Londres (N. del T.).

${ }^{47}$ Gentleman's Magazine 9 (1739): 214, 361-362; S. Perks, The History of the Mansion House (Cambridge: University Press, 1922), 178-87; Sally Jeffery, The Mansion House (Chichester: Phillimore, 1993), 78.

${ }^{48}$ Evening Post, 16 de diciembre de 1721; Post Boy, 2 de enero de 1722. Un tal "señor Cordwell" aparece como miembro de la logia que se reunía en la taberna Queen's Arms en 1725: QCA 10, 32. No queda claro si esta referencia es acerca del Cordwell de esta historia o de su padre, que también fue carpintero pero que murió en 1728 .

${ }^{49}$ Richard Ware padre, fallecido en 1756, de acuerdo con The London Book Trades of the Later 18th Century, (Exeter: Exeter Working Papers in Book History) 10; A catalogue of books, printed for, and sold by Richard Ware, at the Bible and Sun on Ludgate-Hill, removed from Amen-Corner (Londres: ¿1755?).
} 
banquetes anuales que se realizaban en Goose and Gridiron. La primera comunicación trimestral a la que se refiere Anderson fue la realizada el 25 de marzo de $1721^{50}$. Como bien apuntó Begemann, era muy difícil que una reunión trimestral se llevara a cabo el 25 de marzo, día de la anunciación en el calendario cristiano, cuando la gente estaba ocupada en el pago de rentas y renovación de $\operatorname{contratos}^{51}$, ya que, según los libros de minutas, es evidente que la Gran Logia evitaba reunirse ese día ${ }^{52}$. Al parecer, Anderson inventó esta comunicación trimestral para dar certeza de que el duque de Montagu había sido nombrado gran maestro en toda forma. Hay un problema similar con la comunicación trimestral de marzo de 1722, durante la cual, supuestamente, un comité de la Gran Logia aprobó el texto de las Constituciones que se publicaría en 1723. Hay otros puntos en los que es evidente que Anderson inventó detalles para complementar su narrativa. Su reporte del incremento del número de logias entre 1721 y 1722 (12 logias en junio de 1721, 16 en septiembre del mismo año, 20 en diciembre igualmente de 1721 y 24 en marzo de 1722) es sospechosamente regular en su progresión aritmética, y no corresponde con los que sabemos a partir de otras fuentes ${ }^{53}$.

El epítome de las dificultades narrativas de Anderson es la taberna Apple Tree, que es el ejemplo más notorio de su problema con las fechas. Apple Tree existía en 1738, y los archivos de las licencias nos muestran que quien detentaba la de esta taberna era James Douglas, que la había comprado en $1729^{54}$. Sin embargo, a pesar de que se conocen cientos de nombres de tabernas en el Londres de 1716 (muchas de ellas con variantes del nombre "Apple Tree"), no hay referencia alguna a la Apple Tree de Charles Street; al parecer, este nombre se lo puso Douglas cuando tomó posesión de la propiedad en 1729. Como apunta W. J. Williams, los libros de registros muestran que Apple Tree estaba en el lado este de Charles Street, en la esquina con York Street ${ }^{55}$. Este sitio corresponde en la actualidad con el número 28 de Wellington Street, esquina con Tavistock Street, y el local lo ocupa un restaurante de la cadena "Bella Italia". Los dueños anteriores de este establecimiento fueron Robert McClure - de 1713 a 1719- y

\footnotetext{
${ }^{50}$ Book of Constitutions, 1738, 111. Anderson describe confusamente la reunión del 24 de junio de 1721 como banquete y como comunicación trimestral.

${ }^{51}$ El día de la anunciación, "Lady Day" en inglés, fue hasta 1752 (cuando el gobierno británico adoptó el calendario gregoriano) el primer día del año. Los contratos de arrendamiento de la época tenían vigencia de un año, e iban del "Lady Day" de un año al del siguiente (N. del T.)

${ }^{52}$ Begemann, Early History, 609.

${ }^{53}$ Begemann, Early History, 610.

${ }^{54} \mathrm{La}$ primera referencia de la Apple Tree en los registros de licencias de Westminster data de 1729, cuando le fue otorgada a James Douglas: London Metropolitan Archives, WR/LV/1/19. En otra publicación se hace la primera mención de Douglas como licenciatario de la taberna Apple Tree en 1736, véase Westminster City Archives Research Group, One on Every Corner: the History of Some Westminster Pubs (Londres: Westminster City Archives, 2002), 64. Este fue el año en que Douglas tomó posesión de su propiedad según consta en los Westminster City Archives, St. Paul Covent Garden Rate Books.

${ }^{55}$ W. J. Williams, “A Masonic Pilgrimage through London”, AQC 42 (1930): 105-106.
} 
Thomas Taylor -entre 1719 y 1729_ ${ }^{56}$. Las licencias, tanto de McClure como de Taylor, eran para operar como posaderos, pero no hay evidencia de que hayan usado el nombre "Apple Tree". Nuestro argumento durante la pasada cátedra Edward A. Sankey, en la Brock University, fue que en 1716 dicho local no era una taberna sino una mercería llamada The Golden Anchor, propiedad de Simon Mayow ${ }^{57}$. Pero una revisión subsecuente de los archivos demostró que The Golden Anchor no estaba en el lugar que después ocupó la Apple Tree, sino en el lado sur de York Street. Sin embargo, la búsqueda de la Apple Tree ilustra la forma en que la narrativa de Anderson es confusa debido a sus invenciones y sus actualizaciones de nombres de personas y lugares, en las que verdades a medias se entremezclan con hechos inventados a propósito. A pesar de que algunos nombres de tabernas han pasado de una generación de licenciatarios a otra -aún hoy se puede beber algo en The Coach and Horses, cuyo nombre data de 1736-, el nombre Apple Tree parece haber sido exclusivo de James Douglas, ya que desapareció después de su muerte en $1753^{58}$.

Anderson distorsionó e inventó su narración porque la Gran Logia se lo pidió. En la edición de 1723 de las Constituciones, Anderson intenta demostrar que el origen la masonería se puede rastrear hasta el inicio de los tiempos, pero es muy vago en su relato acerca de la sucesión de grandes maestros desde la antigüedad. El 31 de marzo de 1735, la Gran Logia aprobó una moción en la se expresaba "el deseo de que el Dr. James Anderson imprima los nombres (en su nuevo libro de Constituciones) de todos los grandes maestros que pueda hallar desde el principio de los tiempos, así como una lista con los nombres de todos los grandes maestros suplentes, de los grandes vigilantes y de los hermanos que hayan servido a la orden en calidad de expertos"59. Anderson recibió estas instrucciones para que, en el futuro, todos los oficiales de la logia se seleccionaran a partir de estas listas. Esta medida fue diseñada para marcar la exclusividad social del grupo y para evitar que algún oficial cayera en la indigencia y solicitara ayuda caritativa de la logia, como había sucedido con Sayer y con Joshua Timson, el arruinado zapatero y herrero que fue vigilante en la misma época que

\footnotetext{
${ }^{56}$ Al parecer, James Douglas era yerno de Taylor. Thomas Taylor bautizó a su hija Mary en St. Paul Covent Garden en 1708. James Douglas se casó con Mary Taylor (aunque no sabemos si en realidad era la hija de Thomas) en 1728, justo cuando Thomas Taylor cedió la propiedad del local en Charles Street. Douglas bautizó cuatro hijos en St. Paul Covent Garden entre 1729 y 1733. Thomas Taylor reaparece en los registros como licenciatario de una propiedad en la cercana Brydges Street, también en Covent Garden, en 1729: London Metropolitan Archives, WR/LV/1/19.

${ }^{57}$ The Golden Anchor se menciona en espacios publicitarios en el Daily Courant, del 16 de enero de 1718, en el Original Weekly Journal, del 1 de marzo de 1718, y nuevamente en el Daily Courant, del 22 de noviembre de 1722 .

${ }^{58}$ La última referencia de la Apple Tree que quedó registrada fue en 1751: London Metropolitan Archives, WR/LV/1/24. A partir de este punto, el nombre de Douglas se reemplazó por el de John Lemman. Un James Douglas fue enterrado en St. James Piccadilly en 1753: "England, Middlesex, Westminster, Parish Registers, 1538-1912”. City of Westminster Archives Centre, Londres, FHL microfilm 1042313.

${ }^{59}$ QCA 10, 251.
} 
Anderson $^{60}$. Asimismo, la Gran Logia estaba, sin duda, enterada de los planes que se forjaban para establecer una gran logia en Escocia y, por tanto, debía apresurarse para establecer su primacía.

Otra consideración que llevó a Anderson a enfatizar las continuidades en la historia de la Gran Logia, fue la forma en la que esta organización se inclinó hacía la oposición "patriótica" contra el gobierno de Walpole, la cual se centraba alrededor de la figura de Federico Luis, el príncipe de Gales ${ }^{61}$. Esta tendencia era impulsada por Desaguliers, a quien el príncipe le había otorgado un espacio en Kew Palace para instalar su equipo de laboratorio ${ }^{62}$. La dedicatoria y la presentación de la edición de 1738 de las Constituciones al príncipe de Gales, fueron señales inequívocas de apoyo en un momento en el que el heredero al trono había caído de la gracia de su padre y era visto por la oposición como la última esperanza para restablecer el orden que se había perdido debido a la corrupción de Walpole ${ }^{63}$. Bajo la influencia del libro Remarks on the History of England, escrito por Henry St John Bolingbroke en 1730, la oposición "patriótica" resaltaba la importancia "del sentido de continuidad y orgullo que representan el ser británico", así como la consciencia de las tradicionales libertad e independencia británicas ${ }^{64}$. La historia de la masonería escrita por Anderson tenía el fín de mostrar a la organización como profundamente arraigada en la tradición inglesa, pero revitalizada por la casa de Hannover.

De no ser por el tardío y sospechoso testimonio de Anderson y por la lista de oficiales en los libros de minutas, se pensaría que la Gran Logia se fundó en 1721. No existen referencias contemporáneas a la Gran Logia entre 1717 y 1721: ni un reporte en la prensa, ni un solo panfleto antimasónico, ni una mención en algún diario privado, ni una sola obra teatral satírica ${ }^{65}$. Parecería que, en Inglaterra, la masonería entró abruptamente en escena en 1721. Otras dos fuentes nos ofrecen una explicación muy sencilla: la Gran Logia se fundó, en realidad, en 1721. Estas fuentes son los escritos del

\footnotetext{
${ }^{60}$ St. Clement Danes, Pauper Settlements, Vagrancy and Bastardy Examinations, 13 de noviembre de 1742, ref. WCCDEP358180037-38; QCA 10, 123, 130, 134.

${ }^{61}$ Berman, Foundations, 174-175.

${ }^{62}$ Carpenter, Desaguliers, 45-46.

${ }^{63}$ La presentación del libro ante el príncipe se consignó en los anuncios publicitarios de la obra, por ejemplo, en el London Daily Post and General Advertiser del 3 de noviembre de 1739 y en el Country Journal or The Craftsman del 24 de noviembre de 1739.

${ }^{64}$ Andrew Pink, "Robin Hood and her Merry Women: Modern Masons in an Early Eighteenth-century London Pleasure Garden", Journal of Research into Freemasonry and Fraternalism 4 (2013): 203-206; Christine Garrard, The Patriot Opposition to Walpole: Politics, Poetry, and National Myth (Oxford: Clarendon Press, 1994).

${ }^{65}$ Dada la falta de evidencia sobre la existencia de la Gran Logia en 1721, es importante ser cuidadosos en la datación de los documentos. Por ejemplo, el reporte de una reunión masónica en Pontefract, publicado en el Leeds Mercury y citado por Berman en su obra Foundations, está basada en la calendarización "Old Style" (véase la nota 59), por lo tanto, la fecha correcta debería ser el 16 de enero de 1722. G. D. Lumb, "Extracts from the Leeds Mercury 1721-1729”, Thoresby Society 22 (1915), 187-188. De igual forma, el English Short Title Catalogue data la obra teatral satírica Love's Last Shift or Mason Disappointed como de 1720, pero en realidad fue anunciada en el Stamford Mercury del 6 de junio de 1723 como una obra nueva.
} 
médico, anticuario y filósofo natural William Stukeley y un libro en los archivos de la Lodge of Antiquity. Ambos son contemporáneos y más confiables que las fuentes consultadas en la investigación de Anderson. El cuento de que Sayer, Lamball y otros habían sido oficiales de la logia antes de 1721 fue inventado por ellos mismos, con el fin de obtener dinero del fondo de caridad de la Gran Logia. Si esta accedió a su petición, fue para reforzar sus derechos por sobre las demás logias y para demostrar su propia antigüedad.

Stukeley fue uno de los fundadores de la Sociedad de Anticuarios, y es recordado por sus investigaciones arqueológicas en Avebury y en Stonehenge. Dejó registrado en su diario que, el 6 de enero de 1721, se inició "masón en la taberna Salutation, de Tavistock Street, junto con el señor Collins y el capitán Rowe, quien fabricó la famosa máquina de buceo" "66. La Salutation era una taberna muy conocida del barrio de Covent Garden, justo a la vuelta de la esquina de la Apple Tree, que fue establecida en 1709 y que sobrevivió hasta $1881^{67}$.

No sabemos quién era el señor Collins, pero Jacob Rowe era un capitán de barco y emprendedor de Devon, que patentó una campana de buceo ${ }^{68}$. Pero, lo más sorprendente del relato de la iniciación de Stukeley, lo dejó plasmado en su "commonplace book" "69: "yo era la primera persona que se iniciaba en la masonería en Londres desde hacía muchos años. Tuvimos muchas dificultades para encontrar miembros suficientes para llevar a cabo la ceremonia. Inmediatamente después de esto, tomó gran impulso y todos estaban locos por ser miembros"70. Alrededor de 1750, mientras preparaba un resumen de su vida, Stukeley nuevamente enfatizó la falta de masones en Londres en 1721: "Su curiosidad lo llevó a ser iniciado en los misterios de los masones, sospechando que serían una continuación de los misterios de los antiguos, pero fue difícil hallarlos en número suficiente en todo Londres. Después de esto se

\footnotetext{
${ }^{66}$ Bodleian Library, MS Eng. misc. c.533: f. 34v; W. C. Lukis, ed., The Family Memoirs of the Rev. William Stukeley, M. D. (Surtees Society, 1880), vol. I, 62; David Boyd Haycock, William Stukeley: Science, Religion and Archaeology in Eighteenth-Century England (Woodbridge: Boydell Press, 2002), 175. Una inspección del manuscrito revela que fue redactado por Stukeley en la fecha de los eventos.

67 "Southampton Street and Tavistock Street Area: Tavistock Street", en Survey of London: Volume 36, Covent Garden, 218-222. La taberna Salutation se convirtió en uno de los refugios favoritos del príncipe regente. W. Earle, Sheridan and his Times (Londres: J. F. Hope, 1859), vol. 1, 299-311. Esta taberna no tenía relación alguna con la masonería, a excepción de lo que relata Stukeley sobre su iniciación, y no debe confundirse con la cafetería que estaba sobre la misma calle y que era propiedad del masón Richard Leveridge, error cometido por J. Timbs en su libro Clubs and Club Life in London (Londres: John Graham Hotten, 1872), 434-435, y repetido por E. Beresford Chancellor en The Annals of Covent Garden and its Neighbourhood (Londres: Hutchinson, 1930) 154.

${ }^{68}$ Peter Earle, Treasure Hunt: Shipwreck, Diving and the Quest for Treasure in an Age of Heroes (Londres: Methuen, 2007).

${ }^{69}$ Este es un concepto muy de habla inglesa, que no tiene una traducción directa al español. Se trataba de un cuaderno en el que las personas copiaban fragmentos de obras que hallaban interesantes, apuntaban datos diversos o ideas que venían a su mente o que escuchaban de alguien más. No era precisamente un diario. Podría pensarse más en un "cajón de sastre" o en "cuadernos de todo", como llamó a los suyos la escritora Carmen Martín (N. del T.).

${ }^{70}$ Bodleian Library, MS Eng. misc. e.260: f. 88; Family Memoirs, vol. I, 122; Haycock, 175.
} 
convirtieron en una moda pública, que no solo se extendió por Inglaterra e Irlanda, sino también por toda Europa"71.

El relato de Stukeley, sobre la falta de masones para llevar a cabo su iniciación, es imposible de empatar con la narrativa de Anderson, quien afirma que el número de logias creció rápidamente ${ }^{72}$. La taberna Salutation, donde fue iniciado Stukeley, estaba a unos cuantos pasos del punto de Charles Street donde después se alojaría la Apple Tree. Resulta sorprendente la dificultad para encontrar masones si es que, realmente, una logia se reunía allí. Para Stukeley, el verdadero detonante para el crecimiento de la masonería fue el nombramiento del duque de Montagu como gran maestro en Stationer's Hall, en junio de 1721. A diferencia de Anderson, Stukeley sí asistió a este evento y lo describió así:

Los masones tuvieron una cena en Stationer's Hall, estaban presentes el duque Montagu, lord Herbert, lord Stanhope, sir Andrew Fountaine, etcétera. El Dr. Desaguliers pronunció un discurso. El gran maestro señor Payne mostró un viejo manuscrito de las Constituciones, que obtuvo en el oeste de Inglaterra y que tiene 500 años. Nos leyó un nuevo grupo de artículos que deberán ser observados. El duque Montagu fue electo gran maestro para el año próximo, y el Dr. Beal como suplente" ${ }^{\text {, }}$.

A pesar de que el relato de Stukeley es mucho más sucinto que el elaborado recuento de Anderson, nos aporta detalles importantes. En primer lugar, nos revela que, además de la presencia de lord Stanhope -el futuro cuarto conde de Chesterfieldtambién estuvieron allí lord Herbert - noveno conde de Pembroke- quien era arquitecto y mecenas, gran promotor del palladianismo, y el intelectual sir Andrew Fountaine, responsable de las colecciones de lord Herbert y otro eminente promotor de la arquitectura palladiana ${ }^{74}$. En segundo lugar, Stukeley reporta que George Payne presentó un manuscrito con los "Old Charges". Sabemos que se trataba del manuscrito Cooke $^{75}$ gracias a que Stukeley hizo un dibujo de él y a que dicho manuscrito estuvo bajo resguardo de la Gran Logia en sus primeros años, durante los cuales William Reid

\footnotetext{
${ }^{71}$ Family Memoirs, vol. I, 51.

72 Book of Constitutions, 1738, 111.

${ }^{73}$ Bodleian Library, MS Eng. misc. c.533, f. 35; Family Memoirs, vol. I, p. 64; D. Knoop, G. P. Jones y D. Hamer, The Two Earliest Masonic Manuscripts (Manchester: Manchester University Press, 1938), 55. Otra referencia que hace Stukeley a la cena del 24 de junio de 1721, que había pasado desapercibida previamente, se encuentra en la Bodleian Library, MS Eng misc e. 121: f. 30: "[1721] Junio 24. Cena con el D. Montagu y etcétera en la fiesta de los Masones en Stationers Hall".

${ }^{74}$ Véase T. P. Connor, "Herbert, Henry, ninth earl of Pembroke and sixth earl of Montgomery (c.16891750)" y Andrew W. Moore, "Fountaine, Sir Andrew (1676-1753)", en Oxford Dictionary, nos. índ. 101013033 y 101009994 Berman, Foundations, 105,125,135,179.

${ }^{75}$ Manuscrito fechado hacia el 1450 que mezcla un elogio de la geometría con fragmentos del antiguo testamento para hacer un relato de los orígenes de la masonería operativa. Una transcripción en inglés moderno se puede consultar en http://freemasonry.bcy.ca/texts/cooke.html (N. del T.).
} 
hizo dos transcripciones del documento ${ }^{76}$. El descubrimiento del manuscrito Cooke, que quizás fue considerado como un compendio de "misterios de los antiguos", provocó que Anderson fuera comisionado para rescatar las tradiciones y salvarlas de los "graves errores encontrados en la historia y en la cronología" incurridos por la "ignorancia de los escribas en las edades obscuras e iletradas, antes del renacimiento de la geometría y de la antigua arquitectura"77.

Stukeley asegura que George Payne era gran maestro cuando el duque de Montagu fue electo, pero resulta sorprendente que ni un hombre de ciencia, tan bien conectado socialmente, ni la logia de la taberna Salutation no supieran nada de Payne seis meses antes. ¿Había sido nombrado Payne gran maestro apenas en 1721? De igual forma, los reportes periodísticos nos dicen que entre doscientos y trescientos masones asistieron al banquete en Stationers' Hall, lo cual supone un cambio radical respecto a enero del mismo año. Al parecer, durante la primera mitad de 1721, la masonería realmente tomó "gran impulso" y Stukeley tuvo que ver con esto. En diciembre de 1721, Stukeley participó en la fundación de una logia en la taberna Fountain, en The Strand, de la que fueron miembros el doctor Beal, gran maestro suplente de la Gran Logia, y el mismo Stukeley fue electo gran maestro ${ }^{78}$. Nos relata que, en 1722, esta logia recibió a numerosos personajes ilustres, como al duque de Queensberry, al duque de Wharton, a lord Hinchingbrooke, a lord Dumbarton y a lord Dalkeith ${ }^{79}$. El prestigio social de esta logia también quedo registrado en los reportes sobre masonería en la prensa de la época.

La impresión que nos da Stukeley acerca de la repentina aparición en escena de la Gran Logia, en 1721, queda corroborada con otra fuente que, a pesar de no ser muy conocida, aporta un relato crucial para la historia de la creación de la Gran Logia. Se trata de una copia contemporánea de una minuta que describe la reunión, el 24 de junio de 1721, que se encuentra en los archivos de la logia Antiquity no. 2, la misma logia que se reunía en la cervecería Goose and Gridiron. Este archivo no ha sido suficientemente estudiado, y aprovechamos la oportunidad para agradecer el venerable maestro, al secretario y a los miembros de la logia Antiquity no. 2 que nos hayan otorgado las facilidades para examinar este manuscrito y tomar imágenes de él.

Un evento que constituyó una tragedia para el estudio de la historia de la masonería fue la "noche de la indignación", acaecida en la logia Antiquity en noviembre de 1778, cuando los simpatizantes de William Preston en su disputa con la Gran Logia, robaron archivos y mobiliario ${ }^{80}$. Al momento de este incidente, la logia

\footnotetext{
${ }^{76}$ Knoop, Jones y Hamer, Masonic Manuscripts, 55-57; G. P. Speth, "The Stukeley-Payne-Cooke MS", AQC 4 (1891), 69-70; Family Memoirs, vol. I, no. 18, 64. El dibujo de Stukeley se supone que está junto con sus demás papeles en la Bodleian Library, pero hasta ahora no ha sido localizado.

${ }^{77}$ Book of Constitutions, 1723, 73.

${ }^{78}$ Bodleian Library, MS Eng. misc. c.533, f. 36; Family Memoirs, I, 66.

${ }^{79}$ Bodleian Library, MS Eng. misc. c.533, f. 36v.

${ }^{80}$ W. H. Rylands y C. Firebrace, Records of the Lodge Original, No. 1, now the Lodge of Antiquity, No. 2 (Londres: Harrison, 1911-26), vol. I, 1-14; Colin Dyer, William Preston and his Work (Shepperton: Lewis Masonic, 1987), 67.
} 
tenía en su poder las minutas completas entre 1721 y 1778 , al igual que tres volúmenes con los archivos de los tesoreros y de los tejadores. Los dos volúmenes, que contenían las minutas de 1721 a 1733, están perdidos, y a otros volúmenes se les arrancaron páginas. La pérdida de estos registros es desastrosa. Sin embargo, se conserva un borrador, marcado como "E", que contiene algunas de las primeras minutas. Por fortuna, este tomo se encuentra aún en su encuadernación original, que tiene pegada la tarjeta de Charles Stokes, "Librero en Red-Lyon cerca de Bride-Lane, en Fleet Street". La tarjeta tiene la fecha de 1716, probablemente es la fecha de cuando fue grabada. Stokes era conocido por comercializar el "famoso Tabaco Oftálmico, que se fuma suavemente y es agradable al olfato", al que se le hizo una extensa publicidad a partir de 1720, y las hojas de tabaco se ven en la tarjeta ${ }^{81}$. Stokes, "una persona ingeniosa que ha coleccionado medallas, pinturas y otras curiosidades", murió el 10 de junio de $1741^{82}$. La membresía de Stokes en la logia Antiquity se hace constar en el volumen "E" y, en 1719, fue tutor de geometría, algebra y materias relacionadas junto con Jonathan Sisson $^{83}$.

Gracias a que el tomo y la tarjeta de Stokes sobrevivieron, sabemos que el libro "E" en los archivos de la logia Antiquity es anterior a las acciones de Preston y sus seguidores y que, probablemente, haya sido encuadernado para la logia a principios de la década de 1720. Una buena parte del libro no se utilizó sino hasta años después de su adquisición, ya que también contiene minutas de 1759 a 1767 entre las fojas 9v y 85, además de la contabilidad de la logia desde la foja 148v hasta el final del volumen. Igualmente contiene notas diversas de, por ejemplo, la entrega de una placa para imprimir boletos, en julio de 1751 , o en la foja $7 \mathrm{v}$ el reembolso de los fondos pagados durante una ceremonia trimestral en abril de 1756. En la foja $124 \mathrm{v}$ hay una lista inconclusa de grandes oficiales que es muy interesante, ya que omite incluir a Anderson como primer vigilante en 1723. Sin embargo, esta lista es muy tardía ya que está escrita por la misma persona que apuntó las minutas entre el 11 de junio y el 26 de agosto de 1766. El volumen no escapó ileso de la "noche de la indignación", ya que de las fojas 125 a la 133 hay algunos extractos, escritos en caligrafía de finales del siglo XVIII, que se supone son del libro de minutas de 1721 a 1733 que se encuentra perdido. Como lo señala Wonnacott ${ }^{84}$, están escritos por una mano que no puede ser anterior a $1765 \mathrm{y}$ muchos trazos tienen una marcada semejanza con las notas a pie de página de los trabajos de William Preston, lo que sugiere que son registros que fueron redactados y corregidos bajo su dirección.

\footnotetext{
${ }^{81}$ Por ejemplo, en el Applebee's Weekly Journal del 6 de agosto de 1720. Véase Francis Doherty, A Study in Eighteenth-Century Advertising Methods: The Anodyne Necklace (Lampeter: Edwin Mellen Press, 1992), 349-50.

${ }^{82}$ London Daily Post and General Advertiser, 11 de junio de 1741.

${ }^{83}$ Evening Post, 9-11 de julio de 1719. Jonathan Sisson fue un fabricante de instrumentos para astronomía, navegación e ingeniería, inventó el teodolito moderno (N. Del T.).

${ }^{84}$ W. Wonnacott, 'The Lodge at the Goose and Gridiron', AQC 25 (1912), 168.
} 
Pero, al principio del libro "E", hay dos documentos que pueden ser fechados sin lugar a dudas como de principios de la década de 1720. Después de la reproducción de un retrato del duque de Montagu hecho por John Faber, hay una minuta en la foja 2 que describe el nombramiento del duque en junio de 1721; luego, a partir de las fojas 4-5, hay una lista de miembros de la logia, fechada el 18 de septiembre de 1721 . El principio de esta lista está escrito por la misma persona que escribió la minuta del nombramiento de Montagu. Las adiciones posteriores a la lista, que dejan registro de algunos personajes ilustres de la logia, como el primer conde de Waldegrave y sir Charles Hotham, parlamentario de Beverly ${ }^{85}$, son primero de la mano original y después de una variedad de manos que parecen ser, como en el caso del grabador Benjamin Cole, las firmas de los propios miembros. Las últimas entradas en la lista hacen referencia a las iniciaciones del 15 de marzo de 1725, lo que significa que la lista no puede ser posterior a 1726. La mayoría de los miembros nombrados en la primera sección aparece en la lista de miembros de la logia de la taberna Goose and Gridiron. Otros nombres en la lista de 1725 aparecen como miembros de la logia en la taberna Queen's Arms, que es a donde se mudó la logia de la Goose and Gridiron ${ }^{86}$. Lo anterior nos lleva a pensar que la relación entre ambas logias es más compleja de lo que se creía anteriormente, probablemente dado el papel del duque de Wharton como gran maestro de la logia en Queen's Arms. Sin embargo, la lista de la logia refleja a los miembros a principios de la década de 1720, y fue copiada en el libro "E" en esa época. El nombre del maestro William Esquire parece, a primera vista, un error de redacción, pero posiblemente se trate de un William Esquire que bautizó a su hija Ann en St. Botolph Aldgate en $1710^{87}$. De ser así, se trata del primer maestro de la logia Antiquity.

Ya que la lista de miembros de la logia Antiquity contenida en el libro "E" data de principios de los 1720, se puede presumir que el relato del nombramiento del duque de Montagu, escrito por la misma persona, fue redactado no mucho después de $1721 \mathrm{y}$ cabe, por lo tanto, considerarla como una fuente contemporánea. Esta minuta extiende considerablemente el listado de nobles y caballeros distinguidos que asistieron al evento. Concuerda con la mención de Stukeley sobre la presencia de lord Herbert y sir Andrew Fountaine, así como la de lord Hinchingbrooke ${ }^{88}$, quien después visitaría a Stukeley en

\footnotetext{
${ }^{85}$ Sobre Waldegrave, véase Berman, Foundations, 148-150; sobre Hotham, véase E. Cruickshanks e I. McGrath, "Hotham, Sir Charles, 4th Bt", en The History of Parliament: the House of Commons 16901715, eds. Eveline Cruickshanks, Stuart Handley y D. W. Hayton (Londres: History of Parliament Trust, 2002 [citado el 2 de agosto de 2016]): disponible en http://www.historyofparliamentonline.org/volume/1690-1715/member/hotham-sir-charles-1663-1723

${ }^{86}$ La logia en Queen's Arms fue famosa posteriormente por el patronazgo del Dr. Johnson, de Boswell y de Garrick. En la década de 1720 también se le conocía como King's Arms, pero por cuestiones de consistencia aquí usaremos el nombre más usual y conocido de Queen's Arms.

87 “England Births and Christenings, 1538-1975". Genealogical Society of Utah, Salt Lake City, FHL microfilm 370933.

${ }^{88}$ Sobre Hinchingbroke, véase E. Cruickshanks y S. Handley, "Montagu, Edward Richard, Visct. Hinchingbrooke", en The History of Parliament [citado el 5 de mayo de 2017]: disponible en http://www.historyofparliamentonline.org/volume/1690-1715/member/montagu-edward-richard-16921722; Berman, Foundations, 135.
} 
la logia Fountain. También nos dice que lord Hillsborough, un amigo cercano del duque de Wharton ${ }^{89}$, estuvo presente. La minuta no dice explícitamente que lord Stanhope haya estado presente, pero la entrada "P. Stanhope" tal vez se refiera a él. El William Stanhope que aparece posiblemente sea el hermano menor de lord Stanhope. En el texto también se mencionan un buen número de baronets y caballeros, como sir William Leman, tercer baronet, sir George Oxenden, quinto baronet, parlamentario del partido whig por Sandwich ${ }^{90}$; sir Robert Rich, cuarto baronet, quien en la época era parlamentario por Dunwich y partidario de Walpole ${ }^{91}$, Sackville Tufton, posteriormente séptimo conde de Thanet, y el coronel John Cope, parlamentario por Queenborough y también partidario de Walpole ${ }^{92}$. La mintua también menciona a Christopher Wren hijo, quien después sería maestro de la logia Antiquity, así como a miembros de las logias Goose and Gridiron y Queen's Arms, entre ellos a Richard Boult, Charles Hedges y William Western, un miembro de la Royal Society.

El documento de la logia Antiquity nos muestra que la concurrencia a la iniciación de Montagu fue de lo más granado de la sociedad. Lo más sorprendente es la noticia de que el duque de Wharton asistió también. Esto no era inherentemente improbable, pero un reporte en la prensa, aparecido el 5 de agosto de 1721, afirmaba que Wharton se inició en la masonería en la logia de la taberna Queen's Arms apenas a finales de julio de ese mismo año ${ }^{93}$. Lo anterior pone en tela de juicio la secuencia exacta de los acontecimientos respecto a la iniciación de Wharton, aunque no desacredita el relato de la logia Antiquity ${ }^{94}$. La reunión se describe como "una asamblea general de un gran número de masones", la minuta declara que el duque de Montagu fue electo gran maestro, y juró sobre la biblia, "observar y mantener inviolables en el porvenir todas las franquicias y libertades de los masones de Inglaterra y todos los archivos de la antigüedad en custodia de la vieja logia de San Pablo de Londres".

Mientras que esta minuta tenía la intención evidente de apuntalar las pretensiones de la logia, estas estaban basadas sobre la posesión de los archivos de los Old Charges. En este contexto, que Payne haya presentado un documento muchos más antiguo realmente complicaba todo el asunto. Esto añadió gravedad a la segunda parte del juramento de Montagu: "Firmemente observar y nunca permitir ninguna injerencia

\footnotetext{
${ }^{89}$ Berman, Foundations, 143.

${ }^{90}$ R. Sedgwick, "Oxenden, Sir George, 5th Bt", en The History of Parliament [citado el 5 de mayo de 2017]: disponible en http:/www.historyofparliamentonline.org/volume/1715-1754/member/oxenden-sirgeorge-1694-1775

${ }^{91}$ S. Matthews, "Rich, Sir Robert, 4th Bt", en The History of Parliament [citado el 5 de mayo de 2017]: disponible en http://www.historyofparliamentonline.org/volume/1715-1754/member/rich-sir-robert-16851768; Sommers, "Dunwich: the Acquisition and Maintenance of a Borough", en Proceedings of the Suffolk Institute of Archaeology and History 38 (1995): 317-318; Berman, Foundations, 127-128.

92 A. Newman, “Cope, John", en The History of Parliament [citado el 5 de mayo de 2017]: disponible en http://www.historyofparliamentonline.org/volume/1715-1754/member/cope-john-1690-1760

${ }^{93}$ Robbins, "Earliest Years", 68.

${ }^{94}$ Wonnacott, "Goose and Gridiron", 171. Es probable que no haya habido rituales durante la cena del 24 de junio de 1721, por lo que tal vez ni Wharton ni nadie más haya sido iniciado en esa fecha.
} 
en los Landmarks de las viejas logias de Inglaterra, lo que igualmente será hecho por sus sucesores, quienes estarán sujetos por juramento a hacer esto mismo".

En reciprocidad, las antiguas logias convinieron en renunciar a sus privilegios en favor de este nuevo organismo, que era la Gran Logia:

En este día los masones de Londres, a nombre propio y del resto de sus hermanos de Inglaterra, confieren sus separados y distintos derechos y poderes de congregarse en capítulos, etcétera, presentes en la viejas logias de Londres, a favor de lo que hoy fue públicamente reconocido y notificado a los hermanos reunidos en Gran Logia.

Los maestros de las viejas logias aceptaron y confiaron en nombre de sus logias y todo se juró pertinentemente.

Así, la más completa y detallada descripción contemporánea nos demuestra que el nombramiento del duque de Montagu y el acto de transferencia de los privilegios de las viejas logias londinenses al gran maestro y a la nueva Gran Logia se llevó a cabo, no en la taberna Goose and Gridiron en 1717, sino en la reunión en Stationers' Hall en 1721.

Este relato es convincente no solo por ser más contemporáneo que el de Anderson, sino también porque concuerda con el registro de Stukeley y con la evidencia hallada en la prensa. Al parecer fue George Payne, con ayuda de Desaguliers y tal vez de Stukeley mismo, quien diseñó un esquema para llevar a la masonería a un nuevo nivel social y cultural en los meses previos, además de que consiguió llevar a sus filas a reclutas ilustres como el duque de Montagu y tal vez al duque de Wharton también. Payne fue sin duda quien orquestó toda la operación, preparó los reglamentos del nuevo organismo y tal vez haya sido nombrado gran maestro durante el proceso. Pero el significado de la minuta de la logia Antiquity es muy claro: la Gran Logia no se fundó en la taberna Goose and Gridiron el 24 de junio de 1717 sino cuatro años después, cuando las logias londinenses hicieron una transferencia formal de sus privilegios a la nueva organización, el 24 de junio de 1721 en Stationers' Hall. Por ende, el recuento de Anderson de lo sucedido entre 1717 y 1721 debería descartarse.

La minuta de la logia Antiquity indica por qué la Gran Logia se empeñó en dejar en claro que no estaba en deuda con las demás logias londinenses y en promover una versión alterna de sus orígenes. Pero, ¿qué hay de lo que dijeron Sayer, Lamball y otros respecto a su investidura como grandes oficiales en 1717? ¿De dónde surgieron estas historias? Es factible que Sayer y los demás hayan relatado esta historia con la esperanza de obtener ayuda caritativa de parte de la Gran Logia. Al tiempo que hacían circular sus historias, a principios de la década de 1730, proveyeron de material valioso a William Reid y a James Anderson, quienes tenían instrucciones de demostrar que la Gran Logia era heredera de las tradiciones antiguas. Para entender mejor esta dinámica, es necesario que regresemos a la logia que se supone se reunía en la taberna Apple Tree de Charles Street. 
Para 1723 la logia se ha dicho que se reunía en la Apple Tree tenía su base en la taberna Queen's Head, en Knave's Acre. Este lugar se conocía también como Little Pulteney Street y corresponde actualmente a la parte oriental de Brewer Street, en el barrio de Soho. Strype describió a Knave's Acre como "estrecha y habitada principalmente por comerciantes de cosas viejas y de botellas de vidrio"95. La calle tenía muy mala reputación, había constantes quejas de desórdenes en casas de noche "donde se refugian y entretienen holgazanes sospechosos de ser ladrones, carteristas y otras personas disolutas y malvadas, donde se clama que hay asesinatos, etcétera" ${ }^{\text {" }}$. En la prensa se anunciaba un "remedio contra el paludismo", un polvo que garantizaba curar la fiebre, y se instruía a los potenciales clientes que "subieran las escaleras en Joyner's, en la puerta junto a Queen's Head, en Little Pulteney Street, Knave's Acre"97. Hacía poco que se habían llevado a cabo renovaciones en algunas propiedades alrededor de Knave's Acre ${ }^{98}$, por lo que no queda claro cuánto tiempo llevaba la Queen's Head establecida ahí. A pesar de que la logia en Queen's Head aparece en segundo lugar en las primeras listas de logias y de miembros, se reunía bajo una patente otorgada por la Gran Logia con fecha del 23 de febrero de 1723. Por qué le fue otorgada dicha patente es un misterio. Anderson contó, en 1738, que algunos miembros de Apple Tree se habían mudado a Queen's Head debido a una disputa ${ }^{99}$, pero, dada la poca certeza respecto la logia de la taberna Apple Tree, esta explicación tiene un cierto aire de ofuscamiento. No se puede más que dudar que esta logia se haya reunido en un lugar distinto a la Queen's Head.

Se presume que esta logia consistía principalmente de masones operativos y de artesanos, pero no era así. Su maestro en 1723 era Abraham Rayner, un abogado ${ }^{100}$, y otro miembro de la logia, Moses Jevans, era destilador ${ }^{101}$. No obstante, esta logia no era particularmente adinerada ni respetable. Abraham Rayner estuvo preso en Newgate durante tres años por deudas y se le acusó de intentar estafar a otro reo ${ }^{102}$. Los fragmentos de información acerca de Sayer, quien decía haber sido gran maestro, nos indican que era un hombre en circunstancias extremas. Vivía en el barrio pobre de St. Giles in the Fields, y dependía de la caridad de sus compañeros masones para no morir de frío en el invierno ${ }^{103}$. Su primera esposa, Elizabeth, fue asaltada violentamente por

\footnotetext{
${ }^{95}$ Stow y Strype, Survey, vol. II, 84.

${ }^{96}$ London Evening Post, 20-22 de julio de 1732.

${ }^{97}$ Weekly Journal or British Gazeteer, 22 de febrero de 1729.

98 "Brewer Street and Great Pulteney Street Area", en Survey of London: Volumes 31 and 32, St James Westminster, Part 2, ed. Sheppard (Londres: London County Council, 1963), 116-137; una mujer anciana fue encontrada muerta en el ático de una casa nueva, construida en Knave's Acre, en 1722: Daily Journal, 10 de enero de 1722.

${ }^{99}$ Book of Constitutions, (1738) 185.

${ }^{100}$ Old Bailey Proceedings: Accounts of Criminal Trials, 10 de octubre de 1733, Harvard University Library, ref: t17331010-4.

${ }^{101}$ Según su testameto, fechado el 15 de abril de 1735 .

102 Old Bailey Proceedings Online, 7 de septiembre de 1722, ref. f17331010-1.

${ }^{103}$ A. Calvert, “Antony Sayer”, AQC 14 (1901): 183.
} 
un grupo de mujeres irlandesas en 1736 y murió al año siguiente ${ }^{104}$. En 1739 Sayer contrajo segundas nupcias con Eliza May, una viuda, en una ceremonia sencilla y discreta bajo las reglas de The Fleet ${ }^{105}$. A pesar de todo, al funeral de Sayer, realizado en St. Paul de Covent Garden en 1742, asistió una espléndida cohorte de sus hermanos masones ${ }^{106}$.

Conforme creció la Gran Logia, el manejo de sus fondos para caridad se convirtió en un tema de capital importancia. Desaguliers advirtió, en 1729, que la Gran Logia "no debería admitir personas que se unen a la sociedad solamente como medio de sustento" $" 107$. Lo anterior se convirtió en un tema recurrente. En la comunicación trimestral de 1735, la misma en la que Anderson recibió el encargo de elaborar una lista de grandes maestros para sus nuevas Constituciones, se aprobó una resolución que proveía que, para prevenir que la gente se uniera a la masonería para beneficiarse de los fondos de caridad, todas las peticiones de socorro deberían incluir evidencia de que el solicitante había gozado de "buenas o al menos tolerables circunstancias" mientras había sido masón ${ }^{108}$.

Mientras que la logia de Queen's Head contribuía regularmente al fondo de caridad de la Gran Logia, también era de donde provenían más peticiones de ayuda. El caso de Henry Pritchard, un carpintero de Drury Lane que fue miembro de la Queen's Head y de otras logias londinenses, es ilustrativo. En mayo de 1723 fue enjuiciado por agredir a un hombre llamado Abraham Barret, a quien le fracturó el cráneo por haber insultado a la masonería de manera escandalosa, utilizando un buen número de improperios. El jurado halló culpable a Pritchard, pero dado que la agresión fue provocada, le impuso únicamente una multa de 20 chelines ${ }^{109}$.

La Gran Logia no estaba dispuesta a dejar desamparado a uno de sus miembros que había salido en defensa de la masonería, y realizó una colecta que reunió más de 28 libras ${ }^{110}$. A pesar de tan generosa ayuda, cinco años después Pritchard se vio de nuevo en apuros y recibió ayuda de la logia de Queen's Head ${ }^{111}$. En 1730, Pritchard volvió a solicitar auxilio a la Gran Logia argumentando que había sido masón desde el año 1700. Su petición fue desechada, dado que se le había ofrecido un lugar en el asilo y lo había rechazado $^{112}$. Al año siguiente, Pritchard volvió a solicitar ayuda a la Gran Logia arguyendo su pobreza, ceguera y edad, declarando que había sido masón durante más de

\footnotetext{
${ }^{104}$ Sesiones de la corte de justicia, 17 de enero de 1736; Registro de entierros, St. Margaret, Westminster, 12 de agosto de 1737.

${ }^{105}$ King's Arms Register. Fleet Market, 10 de junio de 1739, Londres, Inglaterra, Registro de matrimonios y bautismos clandestinos, 1667-1754. Estos matrimonios, considerados irregulares bajo la ley de matrimonios de 1753, se realizaban dentro o en las inmediaciones de la prisión The Fleet, de la que nos hemos ocupado anteriormente. (N. Del T.)

${ }^{106}$ London Evening Post, 16-19 de enero de 1742.

${ }^{107}$ QCA 10,105 .

${ }^{108}$ QCA $10,251$.

${ }^{109}$ Daily Post, 18 de mayo de 1723.

${ }^{110}$ QCA 10, 54-55.

111 QCA 10, 115.

${ }^{112}$ QCA 10, 134.
} 
40 años -en esta ocasión dijo que se había iniciado en 1690. Su solicitud fue aprobada, y se acordó que Desaguliers le daría cinco libras de los fondos de caridad y que él mismo se encargaría de ver que Pritchard los usara con prudencia ${ }^{113}$.

El ejemplo anterior demuestra cómo los fondos caritativos de la Gran Logia eran muy atractivos para los miembros que se dedicaban al trabajo físico y la artesanía, y que el manejo discrecional del fondo llevaba a los solicitantes a hacer hincapié en su pertenencia y antigüedad dentro de la masonería. Otro miembro de la Queen's Head que intentó sacar provecho de la caridad masónica fue el mismísimo Sayer. Como vimos anteriormente, su nombre no aparece en la lista de grandes maestros en las Constituciones de 1723. En 1724 fue uno de los primeros en solicitar ayuda de la Gran Logia -aunque en esa ocasión no mencionó su cargo- y su caso fue el detonante para el establecimiento de un fondo caritativo ${ }^{114}$. En abril de 1730, Sayer solicitó nuevamente el socorro de la logia, describiendo sus infortunios y su extrema pobreza, y en esta ocasión sí echó mano del argumento de haber sido gran maestro de una logia. Las opiniones al interior de la Gran Logia se dividieron respecto a la forma en que se ayudaría a Sayer. Algunos estaban dispuestos a ofrecerle 20 libras, mientras que otros pensaban que esta cantidad era demasiado generosa y que debían ofrecérsele únicamente 10 libras. Al final se impuso el punto medio y se le otorgaron 15 libras, pero con la aclaración de que se le prestaría tal ayuda "debido a que había sido gran maestro". Con esto se quería dejar muy en claro que solamente alguien con tanta importancia en la organización podía esperar una ayuda de tal magnitud. Unos meses más tarde, Sayer fue acusado por el maestro y los vigilantes de la logia de Queen's Head de realizar iniciaciones irregulares, afirmando que Sayer había encontrado otra forma de sacar beneficios económicos a su antiguo cargo masónico ${ }^{115}$.

Sayer explotó su calidad de ex gran maestro para beneficio propio, pero la logia de la taberna Queen's Head también tenía motivos para apoyar los argumentos de sus miembros, como Sayer y Pritchard, de haber sido masones desde antes de la fundación de la Gran Logia. En 1729, la Gran Logia reorganizó la numeración de sus logias afiliadas, ordenándolas según la fecha de su constitución. Debido a que la patente de la logia de Queen's Head era de 1723, esto la colocó en el número 11. La logia presentó una queja y solicitó estar más arriba en la numeración, lo cual fue rechazado categóricamente por el gran maestro suplente, Alexander Choke, dado que la Gran Logia tenía sus dudas acerca de las aseveraciones de la Queen's Head y de sus miembros ${ }^{116}$. Poco después, se reformó el comité de caridad de la Gran Logia para incluir en él a los grandes maestros de las logias más antiguas. La pérdida de antigüedad de la Queen's Head afectaba su participación en el comité de caridad, por lo que tenía gran interés en revertir la decisión de la Gran Logia.

\footnotetext{
${ }^{113}$ QCA 10, 208-209.

${ }_{114} Q C A 10,59$.

${ }_{115} Q C A 10,131,137-138$.

${ }^{116}$ QCA 10, 106.
} 
Sayer, Lamball y compañía tejieron las historias acerca de sus cargos dentro de la masonería por el prestigio social y para incrementar sus posibilidades de recibir auxilio económico por parte de la Gran Logia. Asimismo, la logia a la que asistían intentó demostrar su antigüedad por razones similares. Anderson, por su parte, recibió la instrucción de demostrar la antigüedad de la Gran Logia, ante la creciente competencia de las nuevas grandes logias de Dublín y de Edimburgo y para coadyuvar en los planes políticos de la organización londinense. El autor de las Constituciones echó mano de los relatos de Sayer, Lamball y otros porque le resultaban de gran utilidad para este propósito. Se necesitan más investigaciones a fondo sobre el contexto y la fundación de la Gran Logia, en el presente trabajo es imposible cubrir el tema en su totalidad. Nuestra intención es destacar que la Gran Logia no se fundó en la taberna Goose and Gridiron, después de una serie de negociaciones en la Apple Tree, en 1717. Nuestra mejor interpretación, dada la evidencia recabada, es que la Gran Logia se fundó a la par del nombramiento del duque de Montagu como gran maestro, en 1721. Esto pone la visita de Desaguliers a Edimburgo, en agosto de 1721, en un contexto completamente distinto. Pero esa, es otra historia.

\section{Conclusión}

Se nos ha sugerido que deberíamos cerrar esta investigación exhortando a la Gran Logia a posponer sus celebraciones del tricentenario hasta el 2021. Pero esa no es nuestra intención. Preferimos que dicho aniversario sea el evento que detone una mayor investigación sobre la historia temprana de la Gran Logia. Con su narrativa de la Apple Tree y de la Goose and Gridiron, Anderson ha creado un mito excepcionalmente duradero, que muchas otras organizaciones fraternas han adoptado. Por ejemplo, según los miembros del Druid Circle of the Universal Bond ${ }^{117}$, John Toland hizo una proclamación en Primrose Hill para llamar a todos los druidas a reunirse en la taberna Apple Tree de Covent Garden. Así, según la tradición, en septiembre de 1717 quedó fundada dicha orden druídica - de la cual el ya mencionado William Stukeley fue dirigente- en el mismo lugar en que supuestamente se fundó la Gran Logia ${ }^{118}$. Estos mitos fundacionales son muy importantes para todas las organizaciones fraternas, $\mathrm{y}$ Anderson estaba consciente de tal importancia. Como él mismo lo dijo en el prefacio de sus Royal Genealogies, es importante que "cada nación cuente con su propia fábula”.

\footnotetext{
${ }^{117}$ Un breve, pero interesante relato que intenta hermanar los orígenes del Druid Circle con los de la Gran Logia, se encuentra en Society X, "1717: Druidry and the founding of modern Freemasonry" (12 de febrero de 2013 [25 de septiembre de 2017]): disponible en https://5ocietyx.wordpress.com/tag/druidcircle-of-the-universal-bond/ (N. del T.).

${ }^{118}$ Ronald Hutton, Blood and Mistletoe: The History of the Druids in Britain (New Haven y Londres: Yale University Press, 2009), 125-129.
} 


\section{Fuentes primarias sin publicar}

\section{Bodleian Library Oxford}

MS Rawlinson C. 136: masonic album

MS Eng misc. e.260; MS Eng misc. c.533: Papers of William Stukeley

\section{Library and Museum of Freemasonry}

'Book E' in the Records of the Lodge of Antiquity No 2

London Metropolitan Archive

Westminster Licensed Victualler Records

Bedford Estate Records

Westminster City Archive

St Paul Covent Garden Rate Books

\section{Fuentes primarias en línea}

Ancestry, www.ancestry.com

The Burney Newspapers at the British Library (Gale-Cengage), http://www.bl.uk/reshelp/findhelprestype/news/blnewscoll/

Eighteenth Century Collections Online (Gale-Cengage), https://quod.lib.umich.edu/e/ecco/

Family Search, www.familysearch.org

Findmypastw, www.findmypast.com

Internet Archive, www.archive.org

London Lives 1690-1800, www.londonlives.org

The Proceedings of the Old Bailey, 1674-1913, www.oldbaileyonline.org

\section{Fuentes primarias impresas}

The Constitutions of Free Masons. Londres: William Hunter for John Senex and John Hooke, 1723.

Anderson, James. The New Book of Constitutions of the Antient and Honourable Fraternity of Free and Accepted Masons. Londres: Caesar Ward and Richard Chandler, 1738.

Anderson, James. News from Elysium or Dialogues of the Dead. Londres: J. Cecil and F. Noble, 1739.

Entick, John. The Pocket Companion and History of Free-Masons. Londres: J. Scott, 1754. 
Knoop, D., G. P. Jones y D. Hamer. The Two Earliest Masonic Manuscripts. Manchester: Manchester University Press, 1938.

Lukis, W. C. ed. The Family Memoirs of the Rev. William Stukeley, M. D. Durham: Andrews \& Co., 1882.

Songhurst, W. J. ed. The Minutes of the Grand Lodge of Freemasons of England, 17231739. Londres: Quatuor Coronati Antigrapha 10, 1913.

Stow, John y Strype, John. A Survey of the Cities of London and Westminster. Londres: A. Churchill, J. Knapton, etc., 1720.

\section{Bibliografía}

Appleby, John H. "Erasmus King: Eighteenth-Century Experimental Philosopher". Annals of Science 47 (1990): 375-392.

Begemann, Wilhelm. Vorgeschichte und Anfänge der Freimaurerei in England. Berlín: E. S. Mittler, 1909-1910.

Beresford Chancellor, Edwin. The Annals of Covent Garden and its Neighbourhood. Londres: Hutchinson, 1930.

Berman, Ric. The Foundations of Modern Freemasonry: The Grand Architects Political Change and the Scientific Enlightenment. Brighton: Sussex Academic Press, 2012.

Boyd Haycock, David. William Stukeley: Science, Religion and Archaeology in Eighteenth-Century England. Woodbridge: Boydell Press, 2002.

Calvert, A. F. The Grand Lodge of England 1717-1917. Londres: Herbert Jenkins, 1917.

Calvert, A. F. “Antony Sayer”. Ars Quatuor Coronatorum 14 (1901): 181-184.

Carpenter, Audrey T. John Theophilus Desaguliers: A Natural Philosopher, Engineer and Freemason in Newtonian England. Londres y Nueva York: Continuum, 2011.

Clayton, Timothy. "Du Bosc, Claude (b. 1682, d. in or after 1746)". En Oxford Dictionary of National Biography. Oxford: Oxford University Press, 2004.

Connor, T. P. "Herbert, Henry, ninth earl of Pembroke and sixth earl of Montgomery (c.1689-1750)". En Oxford Dictionary of National Biography. Oxford: Oxford University Press, 2004.

Day, W. G. "Caesar Ward's Business Correspondence". En Proceedings of the Leeds Philosophical and Literary Society, Literary and Historical Section 19 (1982): 1-8.

Dyer, Colin. William Preston and his Work. Shepperton: Lewis Masonic, 1987.

Earle, Peter. Treasure Hunt: Shipwreck, Diving and the Quest for Treasure in an Age of Heroes. Londres: Methuen, 2007.

Earle, W. Sheridan and his Times. Londres: J. F. Hope, 1859.

Ferdinand, C. Y. "Ward, Caesar (bap. 1710, d. 1759)". En Oxford Dictionary of National Biography. Oxford: Oxford University Press, 2004. 
Gatrell, Vic. The First Bohemians: Life and Art in London's Golden Age. Londres: Allen Lane, 2013.

Gerrard, Christine. The Patriot Opposition to Walpole: Politics, Poetry, and National Myth. Oxford: Clarendon Press, 1994.

Gould, R. F. The Four Old Lodges, Founders of Modern Freemasonry, and their Descendants. Londres: Spencer's Masonic Depot, 1879.

Gould, R. F. "Fortitude and Old Cumberland Lodge No. 12". En Collected Essays and Papers relating to Freemasonry. Belfast y Londres: William Tait, Spencer \& Co., 1913.

Hayton, D. W., Eveline Cruickshanks y Stuart Handley eds. The History of Parliament: the House of Commons 1690-1715. Londres: History of Parliament Trust, 2002.

Hutton, Ronald. Blood and Mistletoe: The History of the Druids in Britain. New Haven y Londres: Yale University Press, 2009.

Jeffery, Sally. The Mansion House. Chichester: Phillimore, 1993.

Lane, Joan. Apprenticeship in England 1600-1914. Londres: UCL Press, 1996.

Linnane, Fergus. Madams: Bawds and Brothel Keepers of London. Stroud: Sutton Publishing, 2005.

Lumb, G. D. "Extracts from the Leeds Mercury 1721-1729”. Thoresby Society 22 (1915): 185-233.

Moore, Andrew W. "Fountaine, Sir Andrew (1676-1753)". En Oxford Dictionary of National Biography. Oxford: Oxford University Press, 2004.

Perks, S. The History of the Mansion House. Cambridge: University Press, 1922.

Pink, Andrew. "Robin Hood and her Merry Women: Modern Masons in an Early Eighteenth-century London Pleasure Garden". Journal of Research into Freemasonry and Fraternalism 4 (2013): 203-214.

Porset, Charles y Cécile Revauger. Le monde maçonnique des Lumières: EuropeAmériques \& Colonies, Dictionnaire prosopographique. París: Editions Champions, 2013.

Prescott, Andrew. "The Publishers of the 1723 Book of Constitutions". Ars Quatuor Coronatorum 121 (2008): 147-162.

Raven, James. "The Book Trades". En Books and their Readers in Eighteenth Century England: New Essays, Isabel Rivers ed. Leicester: Leicester University Press, 2011.

Robbins, A. "The Earliest Years of English Organized Freemasonry". Ars Quatuor Coronatorum 22 (1909): 67-89.

Rutledge, John. The Dialogue of the Dead in Eighteenth-Century Germany. Frankfurt y Bern: Herbert Lang, 1974.

Rylands, W. H. y C. Firebrace. Records of the Lodge Original, No. 1, now the Lodge of Antiquity, No. 2. Londres: Harrison, 1911-1926.

Sammons, Christa. "David Fassmann's Gespräche in dem Reiche derer Todten”. Yale University Library Gazette 46 (1972): 176-178. 
Sedgwick, Romney ed. The History of Parliament: the House of Commons 1715-1754. Londres: History of Parliament Trust, 1970.

Shaaber, M. "The Meaning of the Imprint in Early Printed Books". The Library 25 (1944): 120-141.

Sher, Richard. The Enlightenment and the Book: Scottish Authors and their Publishers in Eighteenth-Century Britain, Ireland and America. Chicago y Londres: University of Chicago Press, 2006.

Sheppard, F. H. W. ed. Survey of London: Volume 36, Covent Garden. Londres: London County Council, 1970.

Sommers, Susan. "Dunwich: the Acquisition and Maintenance of a Borough". Proceedings of the Suffolk Institute of Archaeology and History 38 (1995): 317330.

Sommers, Susan y Andrew Prescott. "New light on the life of James Anderson". En Reflections on Three Hundred Years of Freemasonry. Editado por John S. Wade. Surrey, UK: Lewis Masonic, 2017.

Timbs, J. Clubs and Club Life in London. Londres: John Graham Hotten, 1872.

Westminster City Archives Research Group. One on Every Corner: the History of Some Westminster Pubs. Londres: Westminster City Archives, 2002.

Williams, W. J. “A Masonic Pilgrimage through London”. Ars Quatuor Coronatorum 42 (1930): 70-114.

Wonnacott, W. "The Lodge at the Goose and Gridiron". Ars Quatuor Coronatorum 25 (1912): 165-230. 